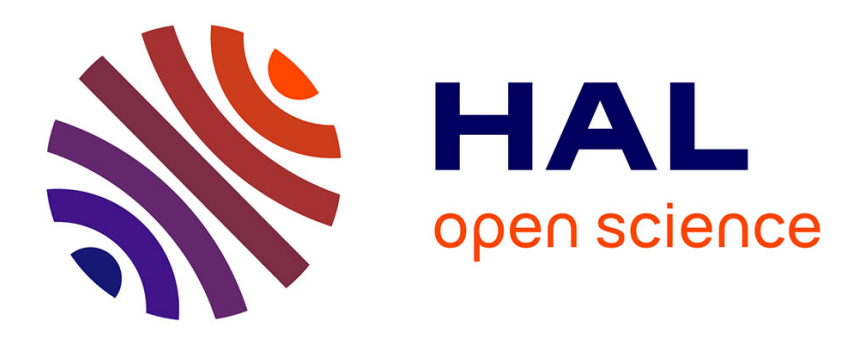

\title{
Giving Birth in Exile: Motherhood as Reterritorialization
}

Elise Pestre

\section{To cite this version:}

Elise Pestre. Giving Birth in Exile: Motherhood as Reterritorialization. American Journal of Psychoanalysis, 2015. hal-01431785

\section{HAL Id: hal-01431785 \\ https://hal.science/hal-01431785}

Submitted on 11 Jan 2017

HAL is a multi-disciplinary open access archive for the deposit and dissemination of scientific research documents, whether they are published or not. The documents may come from teaching and research institutions in France or abroad, or from public or private research centers.
L'archive ouverte pluridisciplinaire HAL, est destinée au dépôt et à la diffusion de documents scientifiques de niveau recherche, publiés ou non, émanant des établissements d'enseignement et de recherche français ou étrangers, des laboratoires publics ou privés. 
Giving Birth in Exile: Motherhood as Reterritorialization

\section{Elise Pestre}

Paris Diderot University at Sorbonne Paris Cité

UFR “Etudes Psychanalytiques," Bâtiment Olympe de Gouges

Place Paul Ricoeur

75205 Paris cedex 13, France

elise.pestre@gmail.com, +336 9867-5153 
This paper explores the effects of exile on the subjectivity of pregnant migrant women through the lens of the processes of deterritorialization and reterritorialization. Having escaped the gaze of the parental superego, the subject's encounter with sexuality becomes possible. However, in addition to the emancipatory aspects of migration, we observe particular somatic-psychical effects on reproductive ability. These "exile" pregnancies are generally experienced as difficult and painful, laying bare a symptomatology this is as much psychical as somatic, and which highlights the cost of a desire for independence. In this context, where perinatal risks must be evaluated and treated through an interdisciplinary approach, a clinical accompaniment proves to be indispensable for the maternity to progress smoothly on foreign soil.

Keywords: migration, sexuality, pregnancy, fertility, deterritorialization, clinical approach 


\section{Giving Birth in Exile:}

\section{Motherhood as Reterritorialization ${ }^{1}$}

\section{Introduction}

Based on a study called "The Subjective Effects of Migration on Female Migrants in Situations of Precariousness,"2 which was conducted at a public maternity hospital in Buenos Aires, this paper discusses the possible connections between the territories of the biological body and the body of the drives, arguing that migration is likely to have unique effects on a woman's reproductive ability.

The subjective movement induced by migration seems to have the power to unravel previous configurations of the drive. This initiates processes of deterritorialization, together with a reterritorialization, ${ }^{3}$ which encourage the emergence of new modes of configuration, both psychical and corporeal.

The selected literature shows that the relationship between migration and fertility began to draw increasing attention in the 1990s, following the spread of migratory phenomena related to globalization, particularly from the point of view of English-speaking research in demography. It must be stressed, however, that most of the research dealing with these topics is based on a demographic perspective that perceives regional differences through the lens of ethnicity (Kulu 2005, Singley et al, 1998). In general, these works are often steeped in neo-Malthusian debates on fertility (Neumayer 2006)

\footnotetext{
${ }^{1}$ Elise Pestre, Associate Professor, Paris Diderot University at Sorbonne Paris Cité, member of the Center for Research in Psychoanalysis, Medicine and Society, EAD-3522.

${ }^{2}$ This research was conduced in Buenos Aires in 2009, in close collaboration with the mental health staff of the Ramón Sardá Maternity Hospital (Dr. E. Andina, Dr. S. Naddeo) and the University of Buenos Aires School of Psychology (UBA-Master "Politicas de Migraciones Internacionales").

${ }^{3}$ These neologisms, coined by Gilles Deleuze and Félix Guattari in Anti-Oedipus (1972), denote the way in which these two movements, locked in a permanent dialectical relationship, follow and respond to each other while producing various changes, especially at the level of meaning and of subjectivity more generally. To become deterritorialized is a way of escaping a sedentary position; it is a way "by which 'one' leaves the territory" (Deleuze \& Guattari, 1980, p.559). Reterritorialization, on the other hand, means "re-creating territory" on something "of a different nature" from what one has left behind (Deleuze \& Guattari, 1994, p.67.) Both processes therefore require creativity and novelty.
} 
There is also a large number of clinical studies dealing with the perinatal period in the context of migration, yet the psychological factors which are investigated generally concern the effects of pregnancy on physical and mental health and on the quality of the mother-child bond, rather than pregnancy itself (Battaglini et al., 2002). Here, we need to mention the pioneering work of the Argentine authors L. Grinberg and R. Grinberg (1989), who have explored the sense of distress caused by displacement and linked to "migratory break". The work by S. Akhtar looking at migration's impact on identity, sexuality, marriage and childbirth, is also worthy of note (Akthar 1995). In France, the current studies look at the effects of maternity on foreign soil, and in particular at the possible psychopathological repercussions of the early mother/child bonds in cases of women in situations of precariousness (Davoudian 2007).

This study was carried out in The Ramón Sardá Maternity Hospital ${ }^{4}$, the first neonatal unit in Argentina, which groups together somatic medicine, hospital-based psychoanalysis, and social work. In this maternity unit, by using modalities of clinical work that apply the term kliné quite literally ${ }^{5}$, we were able to experiment with clinicians who moved from one bed to another on the large wards where the women at rest.

Forty patients were interviewed in the course of this qualitative study, which combined psychoanalysis with medicine and a trans-cultural clinical approach ${ }^{6}$. I saw most of these patients for just one research interview, but was able to see eight of them for a longer period. ${ }^{7}$ The women were interviewed in Spanish, the language of the host country.

More than $40 \%$ of the hospital's patients are immigrants (hospital statistics) and most of the interviewees came from Argentina's neighboring countries (Bolivia, Paraguay and Peru). Their average age was just under twenty-five and they had been living on Argentine soil for a period of one to ten years maximum. These

\footnotetext{
${ }^{4}$ The largest maternity hospital in Argentina, located in the south of the capital. Accredited by UNICEF and the Argentinian Ministry of Health, it registers approximately 7000 deliveries per year.

${ }^{5}$ The Greek kliné, from the verb klinein ("slope, lean or recline") means "at the bedside."

${ }^{6}$ Half of the interviewees were hospitalized locally for high-risk pregnancies; the other half were patients awaiting a consultation in the hospital waiting room.

${ }^{7}$ We should specify that this was psychotherapeutic treatment that allowed for in-depth exploration, thanks to the unfolding of a transferential bond, of the clinical signs that were laid out and the effects of the migration process at the level of the pregnancy process.
} 
women had not experienced any psychopathological problems (only one of the patients mentioned had previously undergone psychotherapy).

Since the maternity ward is in a public hospital, consultations were free of charge. Many of these women were living on the outskirts of the city and mostly in highly precarious conditions, in inadequate housing or in slums (34\%).

In the vast majority of cases migration had been driven by economic and social factors, women often crossed the border alone or with a partner. $90 \%$ of those couples that formed later, in the host country, are made up of individuals from the same minority group.

The analysis of the clinical results of this research relies on psychoanalytical research methodology, aiming to understand the unconscious foundations that determine the singularity of a subject's discourse (Pedinielli \& Rouan, 1998). As the clinical setting makes clear, this perspective also builds on Giorgio Agamben's exemplum model: he argues that a case takes on the value of a paradigm precisely due to its singularity, which makes "a new intelligible ensemble [understandable] in a new problematic context." (Agamben 2009, p.218).

\section{Subjective Effects of Border Crossing}

The question of the possibility of childbearing while living abroad gradually became one of the central points of our research. The respondents' discourse reflected a stark contrast between the reality and experience of their reproductive capacities in the host country and in their native land.

Before we focus on the cases that will support the hypotheses put forward in this article, we should mention some general effects that displacement can have on the psychical life of migrants. Clinical practice with exiled patients has revealed an intensification of the reemergence of problematics from childhood, a movement that generates internal reshaping that is sometimes deep-reaching and which is tied to parental imagos (Pestre 2010). The activation of a "translative drive" 8 in the wake of the displacement will favor a circulation of unconscious material between the psychical agencies, along with a lifting of repression. The outcrop of material that moves from the unconscious to consciousness is vividly facilitated. An author like

\footnotetext{
${ }^{8}$ Drawing on Laplanche's formula: the "drive to translate" in Laplanche 1997, p.295.
} 
Falk was already starting to identify this psychical dynamic driven by the migratory movement when he wrote: "However, borders not only symbolize these interpersonal barriers. They may also symbolize internal boundaries" (Falk, 1974, p.653). Crossing a border is here considered in terms of crossing a territorial line that entails a spatio-temporal distance from the natal soil left behind that is as real as it is fantasmatic. This displacement, and the changes that it introduces into both the internal scene and the social bond, sometimes give rise to intense upheavals in the subject.

In the course of our research, one recurrent fact came to light, which accounts for the peculiar configuration of motherhood in the wake of migration: there were many women who were with child shortly after their migration, despite not having wanted to fall pregnant ${ }^{9}$. Indeed, the vast majority of them had not been "planning" to have a child when they found out about their pregnancy. Although they often had no wish to conceive, not long after their arrival they found themselves surprised, even embarrassed, ${ }^{10}$ to discover that they were pregnant. Given that abortions are banned in Argentina, pregnancies generally lead to childbirth, barring accident or illegal termination.

In addition to cases of contraceptive failure, we should note that contraceptives generally seem to have been seldom used by the interviewees. The fact that conception occurred almost immediately after migration stands in stark contrast to the patients' recurring comments, which could be summarized as: "I didn't want to get pregnant and even less so when I'd just arrived in a new country and had to work."

The observed clinical elements become even more remarkable in cases of women who had been unable to conceive in their country of origin, but then did so successfully in the host country. Before moving to Argentina, several of the forty women interviewed had in fact been considered sterile, yet they got pregnant

\footnotetext{
${ }^{9}$ Our clinical study is a qualitative one, with statistical data presented for information purposes only. Even so, we may mention that we were struck above all by the absence of any formulated wish to fall pregnant and the contrasting advent of these pregnancies "in the wake of the migration". The figures themselves are remarkable: of the 40 women interviewed, $78 \%$ became pregnant during the first two years after moving to Argentina. Although all the women were still of reproductive age, it is noteworthy that $42 \%$ became pregnant during the first year of their presence on Argentine soil.

${ }^{10}$ In reference to the Spanish word for "pregnant" - embarazada. This term, which otherwise translates as "ill at ease" or "in a bind," refers to an expression, in the past also commonly used in French, denoting a woman who became pregnant outside marriage.
} 
without any medical intervention very soon after their arrival ${ }^{11}$. The clinician is struck not so much by the high number of cases as by the enigma of this change, which has no scientific explanation and yet emerges at the level of reproductive capacity. This poses a question to doctor and psychologist alike. In cases of such spontaneous disappearance of infertility or sterility, conception proves to be of major scientific interest. Two clinical situations will help illustrate the questions raised by this biological mystery.

\section{The Cases of Mariana and Rosa}

A nurse suggested that I meet Mariana because she found the young woman "strange" and feared that she was developing "a kind of pregnancy denial". When I met this young woman from Paraguay in the waiting room of the maternity hospital, she told me she was still "stunned" by the announcement of her pregnancy. In her home country, this 27-year-old had been diagnosed as infertile due to uterine malformation ${ }^{12}$. She says she "still cannot believe it". When later I ask her to tell me more about how she is feeling, she explains: "I wasn't expecting it at all. Back there [in Paraguay] they told me I couldn't have any [children], that my womb was underdeveloped." Since her first attempts at getting pregnant and starting a family three years ago, while she was still living in Paraguay, she has been with the same partner. About a year ago, the couple settled in Buenos Aires to "find work." Mariana only found out that she was pregnant at about four months. When we meet, she is in her fifth month and her belly is still very small.

During the interview, Mariana tells me that she often has nightmares about the pregnancy: "I dream of ugly things, of losses. It wakes me up from sleep", she says. The signifier "loss" has a strong resonance and testifies to her anxiety at the gap between her desire for a child and the unexpected occurrence of pregnancy. One cannot help but think of her family and loved ones, now living so very far away from her. Her precarious life conditions prevent her from being able to visit them: "I miss my family a lot", she says later.

\footnotetext{
${ }^{11}$ We may add that at least four cases have been identified as presenting this same symptom (statistics for information purposes only).

${ }^{12}$ The patient explained: "My womb was too small." According to the medical file, tests had concluded uterine hypoplasia. Nevertheless, the file provided little detail.
} 
At the biographical level, I learnt that Mariana was the youngest of six siblings. When I questioned her on her life "back there", and in particular on her childhood, she told me that as a girl she was constantly "stuck" to her father. Her mother "had a lot of work with all the children [...]. She had always said that she didn't want any more children after the fifth child, but she had two more: one who was stillborn and then me. I came last." I was struck by the force of her words, and in particular by the barely veiled way in which her mother had ousted her. She quickly emerged in Mariana's words as a figure who had rejected her, thus constasting sharply with the father who pampered her.

The fact that the symptom of infertility suddenly disappears so soon after Mariana's migration raises questions about the unconscious changes associated with the biological capacity of childbearing. Whereas infertility can be deciphered as the symptom of a certain disjunction within the subject, it seems to us that its sudden disappearance in the absence of any medical intervention is evidence of the surfacing of a subjective truth, and in this way reveals the psychical dimensions of infertility ${ }^{13}$. Doesn't this form of temporary sterility, whose somatic causality has not been demonstrated in medical terms, vouch for the predominance of an underlying unconscious conflict that had been hampering the advent of any conception? The relational mode established between Mariana and her parents in her earliest childhood reveals an archaic level of identification and a likely failing of the maternal figure that supported the primary care at this early period of her life. Our hypothesis is that this unconscious material, in besieging the psyche in this way, probably contributed to preventing this young woman from bearing a child, thus revealing the effects of a "leap from the psychical to the corporeal" (Schaeffer 1997, p.191) in the reproductive function. It is hard to authorize oneself to become a mother when one's own mother was unable to constitute herself at an internal level as a good enough figure. Territorial displacement, which here entails a real distancing from the parents, seems to have fantasmatically distanced the young woman from the identificatory fusion with an absent mother who rejects her. Far from the parents' gaze, and in spite of the superego's prohibitive injunction, object libido started to circulate in a different way. Here, deterritorialization is generating

\footnotetext{
${ }^{13}$ Several clinical studies suggest connections between infertility and psychology. For a review, see Greil 1977. Among current work, see Faure-Pragier 1993, Bydlowski 1997, and Stoléru et al. 1996.
} 
effects of reterritorialization in the couple, facilitating an unblocking that gives rise to the advent of a pregnancy that is now possible on foreign soil. The emergence of new identificatory potentialities thus becomes possible and the work of speech linked to progress in the meetings starts to fall into place in favor of a more subjectified experience of her pregnancy. The evolution and the loosening up of her imaginary relation to parental imagos allowed, through the means of expression that the transference offers, an identificatory interplay open to other feminine and maternal figures.

With this displacement, soma and psyche, which have been transported into a new reality, are now reconfigured in a different way. The body becomes capable of breaking the deadlock of infertility, which then allows it to enter a state of gestation.

Unbeknownst to the subject, a new somatic-psychical configuration emerges, encouraging the pregnancy, which is then spontaneously set "underway." The new condition demonstrates the effects of a psychical and somatic translation initiated by migration, stimulating the process of symbolization. Infertility, which previously was securely held in place by repression, is now supplanted by a specific psychical arrangement: by an interweaving of libidinal cathexes at the woman's epicenter, in the incarnation of a new living being. This suggests that the process of creation-procreation does indeed seem to have been facilitated, provoked even, by the subject's physical movement from one place to another.

Within the context of these clinical hypotheses, the case of Rosa proves to be of equal interest. I met this young Bolivian woman of twenty-five during her twenty-day hospitalization. Thirty-two weeks pregnant, she had been hospitalized following a premature break of water. The nursing team steered me in her direction because she seemed to be depressed and "withdrawn". Moreover, she had reportedly complained of having "dark thoughts".

Rosa had come to settle in Argentina with her husband to begin nursing studies. I learnt that for over two and a half years prior to their migration, they had been trying to have a child, but without success. "I thought I could never have a child. But still, everything was functioning correctly inside, so the doctor said." A first medical investigation had been performed and no anatomo-physiological anomaly had been diagnosed. Just five months after their arrival in Argentina, she 
learned that she was pregnant. She had been pregnant for nine weeks when she found out. “At first I didn't believe it". When I asked her about her partner, and any possible medical tests on his side, hypothesizing that perhaps the sterility was his, she immediately swept the suggestion aside, replying somewhat enigmatically: "I knew that it was because of me". As we shall see, these comments were to find their full signification later on. The absence of pregnancy was a source of worry for her, but also for those around her. This familial form of pressure to bear children, which could be read between the lines of what she said, had contributed to the couple's wish to leave Bolivia together.

During one interview, as she was speaking about a nagging fear that she might not be able to see the pregnancy through to the end, I learned of the death of her mother shortly after the birth of her second brother when she was five years old. Her mother's accidental death, linked to a pulmonary embolism, had occurred just after the birth, by Caesarian section. She adds that she had no memory of her mother. Relating this episode, Rosa cried and spontaneously made a link between her mother's death and the fear she was feeling today, the cause of her sadness: that of the pregnancy not lasting through to the end and her baby dying. I suggest to her the following hypothesis: they might have encountered difficulties in trying to conceive the baby because bringing a baby into the world was synonymous with dying, as was the case with her mother. I then learnt that the death of her mother had only been mentioned very occasionally by the family. I next suggested to her that probably, for this reason, this very painful death had prevented any manifestation of sadness from her. Rosa listened to me in silence, and was able from this key session forth to begin a labor of symbolization of the major depressive movement she was going through, and thereby to elaborate around this insistent fear of a possible death during the birth of her child.

On the basis of this clinical situation, one cannot help but make a link between the trauma generated by the sudden death of her mother after childbirth and her difficulties to bear a child. How was she to become a mother when giving birth was equivalent to dying? 
We may suppose that the early death of Rosa's mother brought about a "psychical hole"14, against which the Ego actively defends by setting up primary defenses such as splitting. This defensive system would thus have allowed for any risk of psychical disorganization and/or collapse to be avoided. Thereafter, any memory linked to the mother that would likely give rise to depressive affects had not only been swept aside by the family injunction not to "speak about it", but also obliterated by the protective egoic agency. Rosa's subjective engagement in a new filial lineage proved to be too perilous because it meant "giving death" 15 ; moreover, we may add that the patient herself had intuitively felt that she was no stranger to this impeded pregnancy. Following the process of deterritorialization that got underway with her migration, the somato-psychical defenses that had been established started to yield under the flood of unconscious representations rising to consciousness. A subjective breech opened up here, allowing for the stranglehold that her mother's silenced death had over her to be partially kept at a distance. Indeed, it was only "partial" because, though Rosa had managed to fall pregnant on foreign soil, her pathological pregnancy was threatening her, and her child, with the risk of a perinatal death. Thanks to the fact that her mental suffering had been ascertained by the medical team, the hospitalization became the occasion for Rosa to begin truly working through, at a psychical level, her painful past, her present sadness, and her baby in gestation. With this clinical situation, where a patient is suffering from a trauma that occurred in a perinatal context, inter-disciplinary collaboration - between the medical and mental health teams - proved to be essential. Indeed, only detection of patients such as these in a state of narcissistic fragility can allow for the possible avoidance of a trans-generational repetition of the trauma, which would be acted out in the mother's body or that of the child. When it has been impossible for the subject to bind and master the return of the traumatic load that had assailed the Ego as a child, the failure of symbolization by language frequently generates repetition "beyond the pleasure principle" at the very

\footnotetext{
${ }^{14}$ Winnicott D., "Fear of breackdown”, 1974. International Review of Psycho-Analysis, Vol 1(1-2), 1974, 103-107.

15 The announcement - which in any case is always "mortifying" - revives ancient repressed material. As Benslama (2005) puts it, "regardless of the content of the announcement - the arrival of a child, a text, a sacrifice, a new era, etc. - it appears essentially as a revelation of one's overwhelming responsibility before the other, where the very fact of giving life also inherently 'brings death',"
} 
site of descent. To gain access to the possibility of seeing the pregnancy through to its end, Rosa will not only have to remain bed-ridden, but also continue her engagement in a true labor of mourning. Going through this proves to be unavoidable when it comes to allowing her to tolerate the emotive weight of bringing her baby into the world.

In the two clinical cases presented here, the phenomenon of "psychical transparency", which is the state that accounts for a "strong permeability to unconscious representations" and to "mnemonic flashbacks" when pregnancy occurs, surges up unambiguously (Bydlowski, 1997) Furthermore, the slowing down of the repression machine produces a weakening in the defense mechanisms that were operating beforehand.

A first level of interpretation would lead us to think that the fact of crossing the symbolic and imaginary border had an effect on these women's biological and bodily coordinates, encouraging and accelerating, quite unbeknownst to them, the reactivation of the womb and conception.

"In the new country, subjectivity opens up to the transformations of the drive; the impossible is transfigured by the possible, showing us that the subject's deterritorialization has been the undoing of all that a previous territorialization might have achieved" (Sasso \& Villani 2003, p.86). New subjective modalities are elaborated, affording the female migrant the new and unexpected experience of childbearing. Here we can see how the change of place effects the "situation neurosis" and can undo the individual's "characterial formation" (Horney K., Neurotic Personality of Our Time, p.24) by influencing his behaviors in a different way in a new actuality. In the cases of Mariana and Rosa, as in other cases we have met, the movement across borders seems to offer the possibility of significant reshaping at the level of the defenses and the drive, thus allowing pregnancy to occur. These different clinical givens make us think that for some women in a state of migration, as in these two cases, territorial displacement seems to be functioning as a "fertilizing factor." Migration would thus be a facilitating factor for the reproductive ability itself. Nevertheless, these studies will have to be continued on a larger scale to lend further weight to this clinical hypothesis that opens up rich perspectives in the field of perinatal healthcare. 


\section{Territorial Displacement and Sexuality}

Analysis of the discourse of the younger women, and in particular those who moved to Argentina along with their parents ${ }^{16}$, highlights the fact that the event of crossing borders has certain emancipatory aspects, which make it conducive to the encounter with the dimension of sexuality and the associated realization of desires. ${ }^{17}$

What interests us here is to underline how in the process of migration the paternal culture of the studied population, with its traditionally Catholic referents and sexual prohibitions, seems to have been pushed into the background. It is as though the body of drives, which was previously tightly regulated by the culture of origin, suddenly became "unlocked." We should also mention that precariousness, which was the common lot of the women we met, can play a predominant role in their libidinal economy by bringing about circumstances of sexual encounter and by introducing a vulnerability at both the psychical and somatic levels.

This "unlocking" of sexuality, on both the symbolic and the real level, is clearly expressed by the youngest generation of these women, who all give voice in one way or another to their belief that at home, "this would not have happened." We are thinking of Sandra, a young seventeen-year-old Bolivian who is eight months pregnant, telling me: “That's for sure, back home I wouldn't have got pregnant. It's a different culture over there - we don't go out as much. Here the girls are crazy and it's contagious!"

Leaving the native land seems to provoke a certain decline in the authority of the superego, making it easier for the subject to move towards the sphere of the drive. The libido can now circulate freely, without borders, far from the reproachful gaze of the ancestral land. In this sense, migration lessens the restrictions imposed on the subject's enjoyment by the paternal gaze. Nonetheless, the emergence of a "paradox of the fate of the drive" has been deciphered in light of the positioning and the discourse of these women who "fall pregnant" earlier than expected. A certain "oscillation between sexualization and desexualization" (Schaeffer 1997, p.220)

\footnotetext{
${ }^{16}$ This path has also been developed on the basis of my clinical observations on maternity, in particular during my limited participation in a weekly talk group for teenagers.

${ }^{17}$ The impact of migration on women's sexuality has been the object of several articles, notably in gender studies linked to migration studies, but also in the sociological field and even the psychological field. See Espin, 1997.
} 
seems to be manifested by the means of expression that the pregnancy offers, and in many cases has a "desexualizing aim". The sexual risks that these women take look much like a game that has gone wrong, initially designed to "tame the drive", even to try to crush it. Pregnancy seems to have as its ultimate purpose the need to control the strength of the sexual drives through the (pregnant) body, which now becomes locked once more, fantasmatically speaking, albeit in a different way. Further to their quest for identity, which vacillates between the culture of origin and the more "local" culture of the host country, these young women experience "the search for sexual identity and the feminine dimension" (Schaeffer, 1997, p.203). In this sense, pregnancy rears its head as a form of response to this quest for meaning and to the question "who am I?" The search for identity goes through strong ambivalence with respect to the so-called culture of origin, and early pregnancy can symptomatize the presence of a conflict-ridden bond with the family and the society it embodies. In these cases, early pregnancy could be a way of identifying in contradistinction to the mother (Schaeffer, 1997, p.204). The aggressive tonality of identification is translated by the sexual passage à l'acte whose unconscious goal is to remove oneself from this bond, to eliminate it, while maintaining it under tension by means of the erotic charge that persists in the shape of dissatisfaction (the pregnancy).

When maternity comes about, the processes of identification, especially those that lie on the side of primary homosexual identification, can be reactivated and lend support to these young women in their quest for sexual and cultural identity. "What's great here is that there are lots of girls like us; we can understand each other". In the institution that offers hospitality to women, coming together in a community of women, homosexual identification functions as a pact that sometimes manages to stand in for the family bond that has gone awry. The primal relationship, in which primordial alienation from the mother was the main stake, is also reactivated, highlighting the difficult negotiation with the inter-generational life debt (Bydlowski 1997, pp.163-185) that it implies.

As the return of the repressed, gestation emerges in the young woman's body in order to replace the irreconcilable dimension of sexuality.

If the experience of the subject seeking hospitality has been particularly difficult, it could be translated into this creation, within oneself, of a fellow being in a state of becoming. This has protective and containing effects on the foreign. To 
try and mitigate feelings of loneliness and anxiety, the female subject can find imaginary shelter in a place she has herself re/produced.

In pregnancy, this destabilizing and sometimes destructive experience of displacement becomes accentuated and extended to the body itself, despite the fact that, originally, pregnancy was precisely a way to suppress and overcome these feelings, because it is precisely the subject's relation to this inner stranger that is at stake. The internal object that has become tangible in this way refers back to the subject's relation to otherness and thus calls into question the type of relation one has with one's own imagoes.

The depressive state commonly found in pregnant female migrants has been observed in a number of clinical studies (Zelkowitz, Schinazi, Katofsky, Saucier, et al. 2004). Their results show that a "foreign" pregnancy often provokes feelings of sadness and loneliness. Although one of the unconscious goals of this presence in the woman's body is to relieve her anxiety and isolation, to mitigate the nostalgos, pregnancy does not always resolve this nostalgic equation because of the strain it puts on the feeling of "continuity of existence" (Winnicott 1969, p.417), which is developed in the beginnings of one's life. The lessening effect with respect to the mother's holding when she is both a migrant and in a state of precariousness accounts for the necessity of clinical treatment so that holding can be reinforced by the institution, in order for them to be able, thereafter, to take care of their babies (Boukobza, 2003).

Still, in certain cases the womb becomes a kind of intermediary space, which can function as an in-between site, a kind of airlock. Here, the found/created baby seems to form a close bond with the unconscious parts of the future mother's Ego, and the organization of defenses, both physical and psychical, allows the subject to struggle against the uncanniness of separation and the anxiety this often causes. In this sense, Joan Raphael-Leff, talks about a "procreative container" function, suggesting that the space of the maternal belly transforms certain highly toxic beta-elements into detoxified alpha-elements, in reference to Bion's theory (Bion, 1962). Pregnancy would then help to induce a kind of psychical immunity, with the placenta representing a protective and transformative barrier against 
external aggression. ${ }^{18}$ A kind of unconscious psychical injunction therefore leads the female subject, and beyond in the couple's unit, to set up an alter ego, meaning that childbirth in a foreign land is also associated with primary narcissism, need, and self-preservative drives.

The pre-Oedipal mother seems to be summoned by this need to bear a child. In less metaphorical terms, pregnancy can mean a real possibility of the mother's presence: in most cases, we observed that, regardless of their socio-economic situation, mothers do come to see their daughters when the latter are pregnant or once the child is born. The process of pregnancy offers a possibility of creating a new maternal bond through flesh itself, leading to a closer relationship with the mother(-land).

All these hypotheses lead us to conclude that territorial migration has real effects at the level of the woman's unconscious economy. Even below the level of desire, these women appear to be drawn towards this bodily enactment which sometimes takes the form of acting-out.

\section{Conclusion}

Discourse analysis showed that in most of the cases a pregnancy in exile, if it has an internal function with a pacifying aim, as we have mentioned, frequently and paradoxically appeared to be "painful," regardless of whether it proceeded normally or was fraught with complications. This became even more marked when migration had been preceded by a previous pregnancy in the country of origin. In all such cases, the previous pregnancy was spontaneously compared to the present one and the latter was distinguished negatively.

The current pregnancy hurts. The baby's movements are identified as more continuous and unpleasant than those imagined or previously experienced back home during prior pregnancies. For the clinician, these loud somatic manifestations raise questions regarding the subjective experience of pregnancy in exile.

The contrasting discourse of the pregnancies occurring "over there" and those occurring here suggests that the subjective experience of the suffering body must be seen in the context of the migratory experience, as though the act of

\footnotetext{
${ }^{18}$ See Raphael-Leff, 1996. The author speaks about "psychological immunity." I prefer to use the expression "psychical immunity."
} 
crossing borders had become embodied in the woman's own flesh. In many of these immigrant women, feelings of depression in fact manifested themselves through bodily pain. $^{19}$

We frequently observed that the women's desires, wishes, anxieties, fantasies and expectations directly concerned the body, in particular the place containing the unborn child. The defense mechanisms of the mother's somaticpsychical apparatus are closely related to those of the fetus.

For certain psychical configurations, migration becomes kairos: a moment of timely opportunity, which marks a point of inflection - the beginning of something new and unexpected. There is indeed a before and after of migration, and in this study we see this transition at the level of reproduction.

In the context of exile, childbearing helps us to understand how these two events, migration and conception, mutually translate each other. The emancipatory wishes with regard to one's family are closely interlinked with the nostalgic desire for a certain kind of Oedipal and pre-Oedipal past. These wishes are sustained by the context of exile and fulfilled through pregnancy, which amplifies still further their nostalgic significance. The efforts to reclaim something of the native land and one's loved ones are twofold. Although the homeland represents the pater (patria), it is also and especially the mater, the motherland: besides the question of the father, pregnancy also entails a rediscovery of the pre-Oedipal mother ${ }^{20}$, the return of an alienating primary and archaic figure, as we have seen in the case of Rosa, for whom bearing a child can also be a way to "reconcile" herself with her mother who vanished from her life too soon.

In the foreign land, falling pregnant must be understood as being connected with both the ideal and the dimension of lack. Questions of loss and nostalgia are bound with the Ideal as a "narcissistic generator that supplies the dynamics of the subject's existence" (Assoun, 1999). This resonates in the women's discourse; the baby appears as a site of ambivalence that it is inherently difficult to bear: to want/not to want a child, to leave/to stay.

However, reterritorialization is necessarily painful and the feelings of

\footnotetext{
${ }^{19}$ Similar somatic manifestations in migrant and refugee populations have previously been studied in detail. See especially Douville \& Galap 1999 and Pestre 2010.

${ }^{20}$ See Bydlowski's work on the double aspect of the child's pre-Oedipal and Oedipal desire and the process of motherhood, particularly Bydlowski 1997.
} 
depression that sometimes accompany these "foreign" pregnancies often result in difficult childbirths, the experience of exile generating and accentuating feelings and bodily symptoms of this kind. On the other hand, when the impulse to live in another country has been subjectified, it may nonetheless allow the subject, at least sometimes, to create a family where previously no such project could have been entertained. Whether we are speaking of future mothers in situations of deterritorialization, or indeed "local" women, the support which the woman receives from her significant others, especially from the child's father, as well as from clinicians and other professionals, must be particularly solid so that these highly charged reactivations of past material, which are part of the gestation period, may run their course without causing harm to the woman's health or the health of the newborn baby.

The clinical data gathered during this study allows us to observe to what extent, in a migratory context, clinical accompaniment by a psychologist and/or a psychoanalyst proves to be necessary so that the pregnancy can develop in a "good enough" way on foreign soil. The remodelling of identity that is triggered by exile and by the processes of pregnancy can only occur in certain psychical contexts on the condition of putting things into words. This is made possible by the space of listening and symbolization offered by the clinician. Here we can take stock of the importance of "human equipment" in hospitals during the process of subjective reterritorialization and the bonding work between the teams so that holding can be reinforced and the pregnancy in exile can unfold in the best possible way.

\section{References}

Ahmed S., (1999), "Home and away: Narratives of migration and estrangement", International Journal of Cultural Studies; 2; 329.

Agamben G., (2009), A critical introduction, Stanford University Press, 2009, Stanford California, p.218.

Akthar S., A Third Individuation: Immigration, Identity, and the Psychoanalytic Process, J Am Psychoanal Assoc August 1995 43:1051-1084, 
Assoun, P.-L. (1999). Le préjudice et l'Idéal. Pour une clinique sociale du trauma. Paris: anthropos/economica.

Battaglini, A., Gravel, S., Boucheron, L., et al. (2002). "Quand migration et maternité se croisent : perspectives des intervenantes et des mères immigrantes." Service social, 49(1):35-69.

Benslama, F. (2005). “De la responsabilité de l'annonce.” D. Brun. (Ed.) Violence de l'annonce, violence du dire. VIIème Colloque de Médecine et Psychanalyse. Paris: Etudes freudiennes.

Brockerhoff, M., Xiushi Y., (1994). "Impact of migration on fertility in SubSaharan Africa." Social Biology, 41(1-2):19-43.

Brun, C., Mouras, J.-P. et al. (2003). La périnatalité: repères théoriques et cliniques $1^{\text {er }}$ et $2^{\text {ème }}$ cycle. Amphi Psychologie. Rosny-sous-Bois: Bréal.

Boukobza C., (2003), "La clinique du holding. Ilustration de D.-W Winnicott.", Le coq héron, 173, pp.64-71.

Bydlowski, M. (1997). La dette de vie, Itinéraire psychanaytique de la maternité. Paris: PUF.

Bydlowski, M. (2000). “La première maternité.” Adolescence, 18(2), 605-620.

Cairns, J. Jr. (2004). "Sustainability ethics: zero net immigration." The Social Contract XV (1):58-71.

Cernovsky. Z., (1988), "Refugees repetitive nightmare.” Journal of Clinical Psychology, 44(5): 702-707.

Davoudian, C. (2007). "Maternité d'exil.” La clinique lacanienne, 2007/1 (12):6973.

Deleuze, G., Guattari, F. (1994). What is Philosophy? Transl. by Graham Burcell \& Hugh Tomlinson. London: Verso. 
Deleuze, G., Guattari, F. (1972) Anti-Oedipus. London: Continuum, 2004.

Deleuze, G., Guattari, F. (1980). A Thousand Plateaus. London: Continuum, 2004.

Douville, O., Galap, J. (1999). "Santé mentale des migrants et réfugiés en France." Encyclopédie Médico-chirurgicale. Paris: Elsevier, p.880-A-10.

Espin O., Latina realities. (1997) Essays on healing, migration and sexuality. Boulder CO, Westview Press, espíritu, Y.L.

Falk, A. (1974). Border Symbolism. Psychoanal Q., 43:650-660.

Framework. (n.d.). Collins English Dictionary - Complete \& Unabridged 10th Edition. Retrieved August 15, 2012, from Dictionary.com website: http://dictionary.reference.com/browse/framework

Freud, S. (1917). Editor's Note to “On Transformations of Instinct as Exemplified in Anal Erotism”. S.E. XVII. Transl. by James Strachey. London: Hogarth, 125-134.

Freud, S. (1923). The Ego and the Id. S.E. XIX Transl. by Joan Riviere. London: Hogarth, 1-66.

Grinberg L., Grinberg R., (1989). Psychoanalytic Perspectives on Migration and Exile, trans. N. Festinger. New Haven, CT: Yale Univ. Press.

Greil, A1. (1977). "Infertility and psychological distress: a critical review of the literature." Soc Sci Med 1977 (45):1679-1704.

Hervitz H., (1985). "Selectivity, Adaptation, or Disruption? A Comparison of Alternative Hypotheses on the Effects of Migration on Fertility: The Case of Brazil.” International Migration Review, 19(2):293-317.

Horney K., Neurotic Personality of Our Time, New York: W.W. Norton and Company, Inc, 1937.

Kulu, H., (2005), "Migration and fertility: competing hypotheses re-examined", European Journal of Population, 21:51-87. 
Laplanche J., Traumatisme, traduction, transfert et autres trans(es), in Le primat de l'autre en psychanalyse. Travaux 1967-1992, Paris, Flammarion, "Champs", 1997.

Mai, N., King, R., (2009). "Love, Sexuality and Migration: Mapping the Issue(s)." Mobilities, 4(3):295-307.

Morrison, T. (2012). Home: A Novel. London: Chatto \& Windus.

Neumayer, E. (2006). "An empirical test of a neo-Malthusian theory of fertility change." Journal population and environment, 27 (4): 327-336.

Pedinielli J.-L., Rouan G., (1998). "L'entretien de recherche.” L'entretien en clinique, (Ed. By Cyssau C.). Collection Psycho. Paris: In Press, p.101.

Pestre, E. (2010). La vie psychique des réfugiés. Paris: Payot.

Pestre E., Benslama F., (2011) "Translation and Trauma", Recherches en psychanalyse, $\mathrm{n}^{\circ} 11$, pp.18a-28a, Journal of Psychoanalytic Studies. Hosted by the Department of Psychoanalytic Studies, Paris Diderot at Sorbonne Paris Cité University

Pragier, G., Faure-Pragier, S. (1993). "Une fille est analysée: Anna Freud.” Rev. française de psychanalyse, 57:447-457.

Raphael-Leff, J., (1996). 'Pregnancy-Procreative Process, The 'Placental Paradigm' and Perinatal Therapy.” J. Amer. Psychoanal. Assn., 44(S):373-39.

Renik, O. (1993). "Analytic Interaction: Conceptualizing Technique in Light of Analyst's Irreducible Subjectivity.” Psychoanalytic Quarterly, 62: 553-571.

Rey, A. (Ed.) (2001). Le grand Robert de la langue française (2 ${ }^{\text {nd }}$ Edition, 6 volumes). Paris: Dictionnaire Le Robert, p.353.

Sasso, R., Villani, A. (2003). Le vocabulaire de Deleuze. Les Cahiers de Noesis, Vocabulaire de la philosophie contemporaine de langue française 86 (Cahier $\mathrm{n}^{\circ}$ 3). Paris: Éditions Vrin, C.N.R.S. 
Schaeffer J., Le refus du féminin, La sphinge et son âme en peine, PUF, Quadrige, Paris, 1997.

Singley, S. G., Landale, N. S., (1998). "Incorporating origin and process in migration fertility frameworks: the case of Puerto Rican women', Social Forces 76(4):1437-1464.

Stoléru, S. et. al. (1996). "Psychological characteristics of infertile patients: discriminating etiological factors from reactive changes." J. Psychosom Obstet Gynaecol 1996 (17):103-118.

Zelkowitz, P., Schinazi, J., Katofsky, L., Saucier, J.-F et al. (2004). "Factors associated with depression in pregnant immigrant women." Transcultural Psychiatry 41:445-464.

Winnicott, D.-W. (1969). “The Capacity to Be Alone.” Int. J. Psycho-Anal., 39:416420.

Winnicott D.-W., "Fear of breackdown”, International Review of Psycho-Analysis, Vol 1(1-2), 1974, 103-107. 